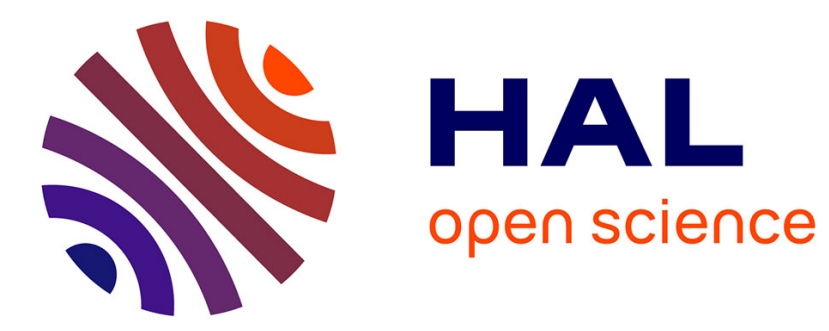

\title{
Born to cope with climate change? Experimentally manipulated hatching time does not affect duckling survival in the mallard
}

Kjell Sjöberg, Gunnar Gunnarsson, Hannu Pöysä, Johan Elmberg, Petri Nummi

\section{To cite this version:}

Kjell Sjöberg, Gunnar Gunnarsson, Hannu Pöysä, Johan Elmberg, Petri Nummi. Born to cope with climate change? Experimentally manipulated hatching time does not affect duckling survival in the mallard. European Journal of Wildlife Research, 2010, pp.505-516. 10.1007/s10344-010-0459-9 . hal00636635

\section{HAL Id: hal-00636635 \\ https://hal.science/hal-00636635}

Submitted on 28 Oct 2011

HAL is a multi-disciplinary open access archive for the deposit and dissemination of scientific research documents, whether they are published or not. The documents may come from teaching and research institutions in France or abroad, or from public or private research centers.
L'archive ouverte pluridisciplinaire HAL, est destinée au dépôt et à la diffusion de documents scientifiques de niveau recherche, publiés ou non, émanant des établissements d'enseignement et de recherche français ou étrangers, des laboratoires publics ou privés. 


\title{
Born to cope with climate change? Experimentally manipulated hatching time does not affect duckling survival in the mallard Anas platyrhynchos
}

\author{
Kjell Sjöberg • Gunnar Gunnarsson • Hannu Pöysä • \\ Johan Elmberg • Petri Nummi
}

Received: 18 June 2010 /Revised: 8 October 2010 /Accepted: 11 October 2010 /Published online: 28 October 2010

(C) Springer-Verlag 2010

\begin{abstract}
Two main hypotheses proposed to explain the seasonal decline in reproductive performance in birds are (1) deterioration of environmental conditions and (2) lower parental quality of late breeders. Previous experimental work addressing these hypotheses generally have problematic biases pertaining to delay of hatching, costs of re-laying and incubation, as well as variation in the quality of eggs, territories, offspring and parental traits. We address these biases in an experimental test of the timing hypothesis (i.e. (1) above) in a precocial bird. Using a 2-year cross-over design and game-farm mallard (Anas platyrhynchos) eggs originating from a number of hens and a standardised delay procedure, we introduced early and late broods with a foster female onto boreal oligotrophic lakes and monitored subsequent duckling survival. Standardised invertebrate sampling was done concurrently to get a measure of lake-level abundance of aquatic prey, a likely causative agent of
\end{abstract}

Communicated by C. Gortázar

\author{
K. Sjöberg \\ Department of Wildlife, Fish, and Environmental Studies, \\ Swedish University of Agricultural Sciences, \\ 90183 Umeå, Sweden \\ G. Gunnarsson $(\varangle) \cdot$ J. Elmberg \\ Aquatic Biology and Chemistry Group, Kristianstad University, \\ 29188 Kristianstad, Sweden \\ e-mail: gunnar.gunnarsson@hkr.se \\ H. Pöysä \\ Finnish Game and Fisheries Research Institute, Joensuu Game \\ and Fisheries Research, \\ Yliopistokatu 6, \\ 80100 Joensuu, Finland \\ P. Nummi \\ Department of Forest Sciences, University of Helsinki, \\ P.O. Box 27, 00014 Helsinki, Finland
}

putative seasonal difference in duckling survival. Survival data and covariates (duckling age; days) were analysed by an information theoretic approach. There was no effect of treatment (i.e. manipulation of hatching date) on duckling survival, which was higher in 2005 than in 2004. In contrast to observational studies from more seasonal wetlands, our experiment demonstrates that duckling survival on boreal lakes was not affected by a 12-day delay in hatching date. Since we did not find any consistent trends in abundance of aquatic prey, i.e. neither clear peaks nor differences between treatment periods, we hypothesise that moderate climate change has minor effects on resource abundance and hence also on mallard duckling survival in boreal environments.

Keywords Breeding biology · Duckling mortality . Mismatch hypothesis · Timing of breeding - Waterfowl

\section{Introduction}

The timing of reproduction is a major fitness-affecting trait in species living in seasonal environments (Clutton-Brock 1988). Considering birds, two general patterns prevail. First, in many species, females that lay later in the breeding season tend to have smaller clutches (e.g. Crick et al. 1993; Hamann and Cooke 1989; Klomp 1970; Rohwer 1992 and references therein), setting an upper limit to the number of offspring that single-brooded species can produce within a season. Second, young that hatch later in the season usually have lower survival (e.g. Norris 1993; Rohwer 1992; Verhulst et al. 1995 and references therein). Two general hypotheses have been proposed to explain the seasonal decline in reproductive performance. According to 'the timing hypothesis', seasonal decline in offspring survival is due to deterioration of environmental conditions, e.g. food 
abundance (Verhulst and Tinbergen 1991; Verhulst et al. 1995). Alternatively, lower survival of late-hatched offspring may be due to lower parental quality of late breeders ('the quality hypothesis'; e.g. Price et al. 1988; Verhulst et al. 1995). The validity of these hypotheses is difficult to assess because smaller late-season clutches may be laid by lower quality females. Experimental manipulations of hatching date have found support for both hypotheses, also within the same species (reviews in Arnold et al. 2004; Nilsson 1999; Verhulst and Nilsson 2008).

Even though earlier experimental studies have found evidence for both environment-driven and parent-qualitydependent seasonal declines in offspring survival, those manipulations themselves have introduced confounding factors that may bias results (discussed in Arnold et al. 2004; Brinkhof et al. 1993; Hansson et al. 2000; Monaghan and Nager 1997). First, experimental delay of hatching is often accomplished by removing the initial clutch to induce a second, thus invoking a re-laying cost in females (Brinkhof et al. 1993; Heaney and Monaghan 1995). Second, manipulation of hatching date usually has involved shortening or lengthening of the incubation period, in which case also the cost of incubation has been manipulated (Brinkhof et al. 1993). Third, egg or chick swaps between nests, a manipulation that does not involve a relaying cost, may be confounded and biased by differences in egg quality, territory quality and parental characteristics (e.g. Arnold et al. 2004; Brinkhof et al. 1993). Finally, although not explicitly discussed in earlier papers, differences in clutch or brood size may introduce additional noise because they usually show a seasonal decline (see above), and offspring mortality may depend on the number of offspring (e.g. Lessells 1991; Lindén and Møller 1989; for precocial species, see Milonoff et al. 1995; Paasivaara and Pöysä 2007; Rohwer 1992).

In the present study, we address the potentially confounding factors mentioned above (either as a part of the experimental design or in subsequent analyses; see "Materials and methods"). We thus provide a more clearcut test of the timing hypothesis by asking whether survival of mallard (Anas platyrhynchos) ducklings depends on the time of hatching. The mallard is an excellent model species in this context. It has uniparental (female) care and ducklings are precocial. Previous experimental studies involving pairs, hens and broods show that it is suited for manipulation, in captivity as well as under field conditions (e.g. Cunningham and Russell 2000; Elmberg et al. 2005a; Gunnarsson et al. 2006; Pöysä et al. 1998; Rhymer 1988; Sjöberg et al. 2000). In addition, the relationship between hatching date and survival in mallard ducklings has been addressed in numerous descriptive studies, and the results are contradicting (see Table 1). The mallard is hence wellstudied when it comes to descriptive patterns of seasonal variation in reproductive success, but experimental work addressing this topic in the species is lacking. As recent reviews indicate (Arnold et al. 2004; Nilsson 1999; Verhulst and Nilsson 2008), experimental work testing the timing hypotheses in birds is strongly biased towards altricial species. We are aware of only one experimental study addressing chick survival in a truly precocial species, namely that by Lepage et al. (1999) on snow geese (Anser caerulescens).

Although research about the seasonal timing of reproduction and its fitness consequences has been ongoing since Perrins' (1970) seminal work, the topic has enjoyed a renaissance due to the effects of global climate change on breeding phenology and other fitness-affecting features in birds and other taxa (Both et al. 2005; Brown et al. 1999; Schoech and Hahn 2008; Visser et al. 1998, 2003; Weatherhead 2005). A general pattern is that climate change advances rather than delays breeding phenology in birds (Both et al. 2004; Dunn and Winkler 1999; Møller 2008; Pearce-Higgins et al. 2005; Torti and Dunn 2005). However, changes in laying date may go in either direction (i.e. advance or delay) even within a species depending on the geographical area (see Both and te Marvelde 2007). It is therefore important to understand how flexible in terms of the width of the breeding time window species are to climate-driven changes in timing. In particular, fitness consequences of climate change are likely to depend on the ability to shift the timing of breeding and resource utilisation to match shifts in resource phenology (the 'mismatch hypothesis'; Drever and Clark 2007; Visser et al. 1998). Accordingly, we will discuss our findings also within the framework of climate change impact.

\section{Materials and methods}

\section{Study lakes}

This study was done in 2004-2005 in Västerbotten province, northern Sweden $\left(64^{\circ} \mathrm{N}, 20^{\circ} \mathrm{E}\right)$. We selected 20 lakes typical for the boreal forest biome, i.e. they were oligo- to mesotrophic and surrounded by mixed coniferous forest and bogs. All lakes freeze over in winter and their breeding waterbirds are long-distance migrants (Fransson and Pettersson 2001). Lakes were selected using the following criteria: (1) no regular human disturbance from cabins, fishing and other outdoor activities during the experiment, (2) roundish or elliptical outline and limited size (mean 3.5 ha, range 1.1-8.2), (3) an easily accessible vantage point from which waterbirds could be observed and surveyed without disturbing them and (4) documented or potential breeding sites for wild dabbling ducks (cf. Kauppinen 1993). 
Table 1 Descriptive studies addressing the effect of timing of hatching on survival of mallard ducklings or broods

\begin{tabular}{|c|c|c|c|}
\hline Reference & Site & Wetland type & Duckling survival \\
\hline Orthmeyer and Ball 1990 & Montana, USA & $\begin{array}{l}\text { Marshes divided into impoundments, } \\
\text { water level manipulated }\end{array}$ & Lower in late broods \\
\hline Rotella and Ratti 1992a & Manitoba, Canada & $\begin{array}{l}\text { Mixture of seasonal, semi-permanent } \\
\text { wetlands }\end{array}$ & Lower in late broods \\
\hline Mauser et al. 1994 & California, USA & $\begin{array}{l}\text { Mixture of permanent and seasonally } \\
\text { flooded marshes }\end{array}$ & No seasonal differences \\
\hline Sayler and Willms 1997 & North Dakota, USA & Lakes, water level manipulated & Lower in late broods \\
\hline Dzus and Clark 1998 & Saskatchewan, Canada & Wetlands of varying permanency & $\begin{array}{l}\text { Lower (here: brood survival) } \\
\text { in late broods in } 3 \text { out of } \\
4 \text { years (higher in } 1 \text { year) }\end{array}$ \\
\hline Krapu et al. 2000 & $\begin{array}{l}\text { North Dakota and } \\
\text { Minnesota, USA }\end{array}$ & $\begin{array}{l}\text { Mixture of lakes and temporary, } \\
\text { seasonal and semi-permanent } \\
\text { wetlands }\end{array}$ & Lower in late broods \\
\hline Gendron and Clark 2002 & Saskatchewan, Canada & Wetlands of varying permanency & No seasonal difference \\
\hline Stafford et al. 2002 & South Dakota, USA & $\begin{array}{l}\text { Mixture of seasonal, semi-permanent, } \\
\text { and permanent wetlands }\end{array}$ & Lower in late broods \\
\hline Hoekman et al. 2004 & Ontario, USA & $\begin{array}{l}\text { Mixture of seasonal, semi- } \\
\text { permanent and permanent wetlands }\end{array}$ & Lower in late broods \\
\hline Pearse and Ratti 2004 & Saskatchewan, Canada & $\begin{array}{l}\text { Range from ephemeral to permanent } \\
\text { wetlands }\end{array}$ & $\begin{array}{l}\text { Lower in late broods in } 1 \text { out } \\
\text { of } 2 \text { years (no difference } \\
\text { in } 1 \text { year) }\end{array}$ \\
\hline Simpson et al. 2005 & $\begin{array}{l}\text { Great Lakes region, } \\
\text { Ohio, Michigan, } \\
\text { Indiana, Wisconsin, } \\
\text { USA }\end{array}$ & Mixture of semi-permanent wetlands & No seasonal difference \\
\hline Chouinard and Arnold 2007 & California, USA & $\begin{array}{l}\text { Mixture of semi-permanent and } \\
\text { permanent wetlands }\end{array}$ & No seasonal difference \\
\hline
\end{tabular}

Eggs, ducklings and introductions

We used a sequence of procedures to standardise the properties of ducklings and broods in the introduction experiment. In both years, mallard eggs were purchased on one occasion in mid-May from one of Sweden's largest game farms, hosting several hundreds of egg-laying wildstrain mallards. All eggs had been laid on the day of purchase, and they were randomly chosen from the farm's daily production. Hence, all eggs were the same age and had been produced by many different females. In order to standardise duckling quality among subsequent broods and treatments, we randomly picked half of the eggs and put them in a cool storage room upon arrival at the Boda Game Station $\left(62^{\circ} \mathrm{N}, 17^{\circ} \mathrm{E}\right.$, some $250 \mathrm{~km}$ NNW from the purchase site). These eggs comprised 'the late treatment' (see below).

At the game station, the remaining half of the eggs were randomly assigned to ten clutches of ten eggs each and put in the nest of an incubating mallard, whose own first clutch (ranging from nine to $13 \mathrm{eggs}$; i.e. the normal span for wild mallards) was taken away at the same time. Each 'foster mother' had been incubating for 5-14 days when the swap occurred, and they had built their own nest in a large fenced outdoor area with natural vegetation and wetlands. These females were locally caught wing-clipped wild-strain birds paired with captive and/or free-flying males. Hence, there was no genetic connection between foster mothers and their subsequent brood. All females accepted their new brood, which hatched 27-28 days later, i.e. the normal incubation time in the wild (Cramp and Simmons 1977). Consequently, females incubated for a longer time than wild females would have done unless re-nesting, but this potential bias was the same in early and late treatments. Moreover, incubating females had access to natural animal and plant food in the wetlands of the pen, but also continuously to commercial fodder. Females therefore had the opportunity to compensate for greater incubation costs, which also was the case if the size of the own (pre-swap) clutch was different from the added clutch, by supplemental feeding.

Meanwhile, 'the late treatment eggs' were stored at $10^{\circ} \mathrm{C}$ (but only for 12 days in order not to reduce viability) and rotated twice daily according to standard game farming procedures. These late treatment eggs were assigned to ten broods of ten eggs each and put in the nest of ten other female mallards in the same outdoor pen. Just like females in the early treatment group, late treatment females had incubated their own first clutch for 5-14 days when the swap occurred. Thus, late treatment females were naturally late-nesting individuals, whereas females in the early 
treatment were natural early nesters. In both years, this second and artificially delayed batch of broods subsequently hatched 12 days after the early batch. Hence, there was not any reason to assume a consistent difference between early and late-brooding females when it comes to laying and incubation costs, i.e. reproductive costs that have been particularly difficult to control for in earlier experiments (Arnold et al. 2004; Monaghan and Nager 1997; Verhulst and Nilsson 2008). We cannot rule out that there might have been some kind of quality difference between the groups of females related to them being either early or late nesters (e.g. Arnold et al. 2004), but it seems unlikely. Batt and Prince (1979) found in a 3-year study with captive mallards (originally reared from eggs taken from wild nests) that the starting date of the first clutch varied considerably between females within a season (43-58 days) and that the repeatability of an individual's clutch initiation date is high from 1 year to the next. This may have several explanations, and one is that female mallards may have a genetically determined propensity for laying earlier or later than the population mean, and if so, differences in natural laying dates may not necessarily reflect differences in quality. Genetically determined inclination for laying earlier or later than the population mean has been found in other waterfowl too, for example, in the common eider (Somateria mollissima; Laurila and Hario 1988). Most importantly, even if there was a quality difference between early and late females, this potential bias apparently did not affect our results (see "Discussion").

In both treatments in 2004 and in the early treatment in 2005, all ducklings hatched successfully and all broods thus comprised ten ducklings. In the late treatment in 2005, however, one female deserted her brood at the farm. In order to obtain a balanced design (i.e. the same number of ducklings in all broods released) for this treatment, brood size was standardised to eight ducklings by reducing the full broods by two arbitrarily chosen ducklings each. These ducklings were then pooled to make up a new full brood (eight ducklings) for the female that deserted her previous brood. All females were weighed and measured (wing and tarsus), and all ducklings were weighed individually within $24 \mathrm{~h}$ of hatching. Body mass was found to differ between early and late treatment females in both years (general linear model, 2004: $F_{1,11}=14.74, p=0.003$; 2005: $F_{1,11}=4.99, p=0.047$; $\mathrm{PC} 1$ scores in a principal component analysis of wing and tarsus lengths were used as a covariate to control for body size differences). However, these differences were in opposite directions in 2004 and 2005, with leaner females in the early treatment than in the late in 2004 (887.7 g [SE=13.0] vs. $1,014.5 \mathrm{~g}$ $[\mathrm{SE}=30.2])$ and heavier females in the early treatment in 2005 (912.5 g [SE=34.7] vs. 878.2 g [ $\mathrm{SE}=28.0]$ ).
Regardless of treatment, females were generally heavier in 2004 (960.1 $\mathrm{g}$ [SE= 24.7]) than in $2005(897.8 \mathrm{~g}$ [SE=22.9]; general linear model, $F_{1,25}=7.94, p=0.009$ ). Duckling body mass differed between early and late treatment in 2004 (early ducklings $29.3 \mathrm{~g}$ [SE=0.4]; late ducklings $33.1 \mathrm{~g}$ [SE=0.3]; independent $t=-7.94, d f=138$, $p<0.001$ ) but not in 2005 (early ducklings $34.0 \mathrm{~g}$ $(\mathrm{SE}=0.4)$, late ducklings $33.3 \mathrm{~g}(\mathrm{SE}=0.7)$; independent $t=0.92, d f=73.4$ [equal variances not assumed], $p=0.36$ ). Duckling body mass was higher in 2005 (33.7 g $[\mathrm{SE}=0.4])$ than in 2004 (31.5 $\mathrm{g}$ [SE=0.3]; independent $t=-5.04, d f=266, p<0.001)$. These analyses of body mass are based on ducklings and hens eventually included in the survival analysis (i.e. data from six lakes were omitted due to unsuccessful introductions; see below).

After weighing, each brood was transported separately with its foster mother from the game station to a randomly assigned study lake in Västerbotten (ca. $350 \mathrm{~km} \mathrm{NE}$ of Boda Game Station), where they were released at dawn the day after, i.e. when ducklings were 24-36 h old. All broods were released successfully in the sense that the foster female and her brood swam out on the lake together in a tight brood formation. In 2004, the early treatment broods were released on June 17 and the late broods on June 29. In 2005, the corresponding dates were June 19 and July 1, respectively. Hence, in both years, early as well as late treatment ducklings hatched within the natural time window of back-calculated hatching dates of local wild mallard broods observed on study lakes and other lakes in the region (2004: range June 3-July 1, $n=8$; 2005: range May 22-July 3, $n=7$; Sjöberg et al., unpublished data).

To account for possible effects of consistent lake-level differences in, e.g. depth and shoreline vegetation, we used a between-year cross-over design, i.e. lakes receiving an early brood in 2004 had a late brood in 2005 and vice versa. In terms of our modelling requirements, the experimental introduction failed in one or both years on six of the lakes in the sense that neither the hen nor the ducklings were observed after the day of introduction. This left us with full data sets from 14 lakes, i.e. 60 ducklings (six lakes) in the early treatment and 80 ducklings (eight lakes) in the late treatment in 2004 and 80 ducklings (eight lakes) in the early treatment and 48 ducklings (six lakes) in the late treatment in 2005. These duckling data were used in the subsequent survival analyses (see "Modelling analysis" below).

All handling of ducks, ducklings and eggs was in compliance with Swedish law. Introductions were done in accordance with permit A19-04 from the Research Animals Ethics Board at the Court of Appeal for North Sweden, Umeå, Sweden. 


\section{Observation of introduced birds}

Generally, most duckling mortality occurs the first 2 weeks after hatching (e.g. Orthmeyer and Ball 1990; Rotella and Ratti 1992a), and each lake was therefore visited daily for 12 days after the release of ducks to count remaining introduced birds.

We used the waterfowl point count method in Koskimies and Väisänen (1991), i.e. 20 min of still observation and scans from a fixed point. Introduced foster females were readily told from wild females due to their lack of primary projection (wing tip) on one of the wings. Most counts were made in the morning or in the evening, when duckling foraging activity normally peaks (Ringelman and Flake 1980). No counts were made at night. Considerable effort was made to approach lakes without alarming the ducks. For practical reasons, it was not feasible to totally randomise the visiting order of lakes. The latter comprised a northern and a southern cluster, between which visit order was alternated. To minimise the distance driven, lakes were visited in a specified sequence within each cluster, the starting end of which was alternated between study days.

\section{Invertebrate trapping}

Previous research has demonstrated a positive correlation between duckling survival and invertebrate prey abundance in breeding wetlands (Cox et al. 1998; Danell and Sjöberg 1977; Hill et al. 1987; Sedinger 1992). Since dabbling ducks consume benthic, nektonic as well as hatching metamorphosing invertebrates, we used two trap types in each lake: (1) six floating emergence traps catching insects leaving their aquatic phase were deployed on shallow water close to the shore and (2) six submerged activity traps catching benthic and free-swimming invertebrates were placed on the bottom in shallow water according to standard procedures (e.g. Elmberg et al. 1993). Both trap types were used continuously from day 0 (introduction day) until day 12 at all lakes, and they were emptied every second day $(48 \mathrm{~h})$. Hence, for both trap types, there were six trapping periods with six traps each, i.e. 36 invertebrate samples from each trap type and study lake. The content of each trap was analysed separately, and all prey were identified to taxonomic order and size class (cf. Elmberg et al. 1993, 2005a; Nudds and Bowlby 1984). Amphibians and typical terrestrial invertebrates found in traps were left out from analysis. Catches from traps containing fish were also omitted, as intruding fish may bias invertebrate samples (Elmberg et al. 1992). Catches were weighted by body length class, and their partial weights were summed and finally standardised to "per 100 trap days" to obtain an invertebrate abundance index value for each trap (for details, see Elmberg et al. 2005a).
Modelling analysis

The modelling input file included an encounter history for each individual duckling for its 13-day study period, i.e. days $0-12$. In order to allow lake-specific covariates in the subsequent modelling (see below), input data were categorised in 28 different groups (i.e. 14 lakes in 2 years).

We used program MARK (White and Burnham 1999) and the Cormack-Jolly-Seber (CJS) modelling option with "live recaptures only" (Lebreton et al. 1992) to analyse duckling survival. Estimates for apparent survival ( $\Phi$; i.e. mortality cannot be distinguished from permanent emigration) as well as for the probability that a duckling was re-sighted $(p)$ were generated by modelling. Ducklings were not individually marked, but the CJS approach was still considered valid because (1) introduced broods were always successfully identified based on the presence of the introduced hen lacking primary feathers, (2) wild mallard broods were seldom present and brood mixing between wild and introduced broods was never suspected and (3) on only a very few $(5.4 \%)$ occasions more ducklings were observed than on the preceding visits at the same lake (indicating that ducklings had been missed - not counted - on previous visits). We consider the latter bias on survival and resighting estimations as minor.

The global model included the dummy variables treatment (i.e. early vs. late introduction) and year, as well as their interaction. Potential lake-level effects could not be evaluated due to over-parameterised models, which was also true for models with full time dependence. However, earlier research in the same study region shows that duckling age is important for survival the first 2 weeks after hatching (Gunnarsson et al. 2004, 2006), and to include such a constraint, the logit-link function was used to be able to add age effects as covariates in the design matrix. Two different effects of duckling age were considered: (1) a linear (this was done by entering the values $0-11$ for the study days) and (2) a quadratic (i.e. the squared products of the linear effect values; cf. Gunnarsson et al. 2004, 2006).

Goodness-of-fit of the global model was evaluated with a bootstrap approach. This was done by first running a simulation of the most parameterised model (covariates excluded; i.e. model \#10 in Table 2) with 500 iterations. The deviance for each iteration was then ranked and compared to the observed deviance for the global model. The observed model deviance was finally divided by the average deviance from the bootstrap simulation, and this quotient was used to adjust the variance inflation factor $(\hat{c})$ in order to control for overdispersion (i.e. lack of fit; Burnham and Anderson 2002). 
Table 2 Live recapture (Cormack-Jolly-Seber) models for apparent survival $(\Phi)$ and re-sighting $(p)$ probabilities of mallard ducklings introduced onto lakes in northern Sweden 2004 and 2005

\begin{tabular}{|c|c|c|c|c|c|}
\hline Model & $\mathrm{QAICc}^{\mathrm{c}}$ & $\Delta \mathrm{QAICc}^{\mathrm{d}}$ & $w_{\mathrm{i}}^{\mathrm{e}}$ & $K^{\mathrm{f}}$ & Deviance $^{\mathrm{g}}$ \\
\hline 1. $\Phi_{(\text {year })} p_{(.)}$ & 357.57 & 0.00 & 0.18 & 3 & 255.15 \\
\hline 2. $\Phi_{(\mathrm{year}+\mathrm{age}[l])} p_{(\mathrm{.})}$ & 357.60 & 0.03 & 0.18 & 4 & 253.15 \\
\hline 3. $\Phi_{(\text {treat }+ \text { year })} p_{(.)}$ & 357.66 & 0.09 & 0.18 & 4 & 253.21 \\
\hline 4. $\Phi_{(\text {year })} p_{(\text {age }[]])}$ & 358.76 & 1.18 & 0.10 & 4 & 254.30 \\
\hline 5. $\Phi_{\text {(year) }} p_{\text {(treat) }}$ & 358.78 & 1.21 & 0.10 & 4 & 254.33 \\
\hline 6. $\Phi_{(\text {year })} p_{(\text {year })}$ & 359.20 & 1.62 & 0.08 & 4 & 254.74 \\
\hline 7. $\Phi_{(\text {year }+ \text { age }[q])} p_{(.)}$ & 359.38 & 1.81 & 0.07 & 5 & 252.88 \\
\hline 8. $\Phi_{(.)} p_{(.)}^{\mathrm{a}}$ & 360.09 & 2.52 & 0.05 & 2 & 259.70 \\
\hline 9. $\Phi_{(\text {year })} p_{(\text {age }[q])}$ & 360.80 & 3.22 & 0.04 & 5 & 254.30 \\
\hline 10. $\Phi_{\text {(treat } \times \text { year })} p_{(\text {trear } \times \text { year })}{ }^{\mathrm{b}}$ & 362.90 & 5.33 & 0.01 & 8 & 250.23 \\
\hline
\end{tabular}

Dummy variables in the models are treatment (treat) and year (year) and their interaction. Two additional continuous covariates were added in the design matrix: linear effect of duckling age (age $[l]$ ) and quadratic effect of duckling age (age $[q]$ ) (additional to the linear effect). A multiplication sign indicates the interaction term between two variables along with their separate effects. See footnotes for model details and "Modelling analysis" for a more thorough description of the modelling procedure

${ }^{\text {a }}$ Model including the intercepts only

${ }^{\mathrm{b}}$ Most general model (excluding covariates) with all parameters estimated with precision

${ }^{c}$ Quasi-likelihood Akaike's information criterion adjusted for low sample size

${ }^{\mathrm{d}}$ Difference between QAICc of the current model and the minimum QAICc value

${ }^{\mathrm{e}}$ Normalised Akaike weight

${ }^{\mathrm{f}}$ Number of parameters

${ }^{\mathrm{g}}$ Difference in $-2 \log ($ likelihood) of the current model and $-2 \log ($ likelihood) of the saturated model (i.e. the model containing as many parameters as the sample size)

To find more parsimonious models, variables of minor importance were dropped consecutively from the global model, as judged by the change of the quasi-likelihood Akaike's information criterion with adjustment for low sample size (QAICc). Competing models within two QAICc units were considered as potential best models, unless higher-ranked models were a hierarchical subset of a lower-ranked model. If the latter was true, the more complex and lower-ranked model was excluded (Burnham and Anderson 2002; see also Arnold 2010). The $\Phi$ parameters were considered first, followed by the $p$ parameters (cf. Doherty et al. 2002). The two age covariates were added as constraints to the highest ranked model in the candidate set.

In Table 2, we report the global model (used for the bootstrap simulation), the model including the intercept only, the highest ranked model and finally the models needed to validate the variables not included in the highest ranked model. This validation was done by including those variables to the highest ranked model one at a time. For evaluation of the variables among the highest ranked models, $\beta$ values with SEs were considered. Modelaveraged real estimates are presented for survival and resighting probabilities in Fig. 2.

\section{Results}

Duckling survival

Goodness-of-fit testing revealed that the global model did not adequately fit the data, i.e. deviances from the bootstrap simulation were all ranked lower (highest deviance was 390.92) than the observed deviance (924.74). Overdispersion was controlled accordingly by adjusting $\hat{c}$ to 3.70 , i.e. the deviance from the global model was divided by the average deviance from the bootstrap simulation (i.e. 924.74/250.23).

Excluding parameters of minor importance from the global model resulted in more parsimonious models. For the survival $(\Phi)$ parameters, the highest ranked model included the year effect only. Evaluation of the beta estimates revealed that survival probability was higher in 2005 than in $2004(\beta=0.70 ; \mathrm{SE}=0.33)$. The other variables were included in lower-ranked models, which despite relatively high model weights confirm that all variables except year were of minor importance. This was based on the high variation relative to the $\beta$ values: treatment $(\beta=-0.47 ; \mathrm{SE}=0.34)$, linear effect of duckling age $(\beta=0.12 ; \mathrm{SE}=0.09)$ and quadratic effect of duckling age 
$(\beta=-0.02 ; \mathrm{SE}=0.03)$. Moreover, model-averaged estimates for survival (Fig. 1) confirmed that year was the only variable of importance to survival.

For the re-sighting probability $(p)$, none of the variables was among the highest ranked models. beta values from lower-ranked models made it clear that no variable was of great importance to re-sighting probability: treatment $(\beta=-0.36 ; \mathrm{SE}=0.39)$, year $(\beta=-0.28 ; \mathrm{SE}=0.43)$, linear effect of duckling age $(\beta=0.06 ; \mathrm{SE}=0.07)$ and quadratic effect of duckling age $(\beta<-0.01 ; \mathrm{SE}=0.02)$. Modelaveraged real estimates for re-sighting probabilities confirm these findings (Fig. 1).

Invertebrate abundance

Invertebrate abundance varied markedly among the 14 lakes (Fig. 2). The abundance indices of emergence trap catches did neither vary between treatments in either of the years nor between years in the two treatments (independent $t$ test: $p>0.49$ ), and the overall mean for 100 trap days was 648.3 ( $\mathrm{SE}=105.8)$. The abundance indices of invertebrates caught in activity traps were higher in the early treatment $($ mean $=1,232.6[\mathrm{SE}=189.2])$ than in the late $($ mean $=658.1$
[SE=173.6]) in 2004 (independent $t=2.22, d f=12, p=0.05$ ), but not in 2005 (independent $t=-1.69, d f=5.27$ [equal variances not assumed], $p=0.15$; overall mean in $2005=$ 1,653.6 [SE=527.8]). Abundance indices from activity traps did not differ between years in either treatment (independent $t$ test: $p>0.12$ ).

\section{Discussion}

Our manipulation of hatching time did not corroborate the timing hypothesis predicting that survival in late-hatched mallard ducklings should be lower than in those hatched early. Some previous observational mallard studies have found lower duckling survival in late broods than in early, but a lack of a seasonal effect and even opposite trends have also been reported (see Table 1). Although there are no pertinent previous mallard studies from the study region, there are indeed inconsistent patterns in other species that have been studied there. Elmberg et al. (2005b; observational study) reported higher breeding success in early nesting Eurasian teal (Anas crecca crecca), whereas Paasivaara and Pöysä (2007; observational study) did not
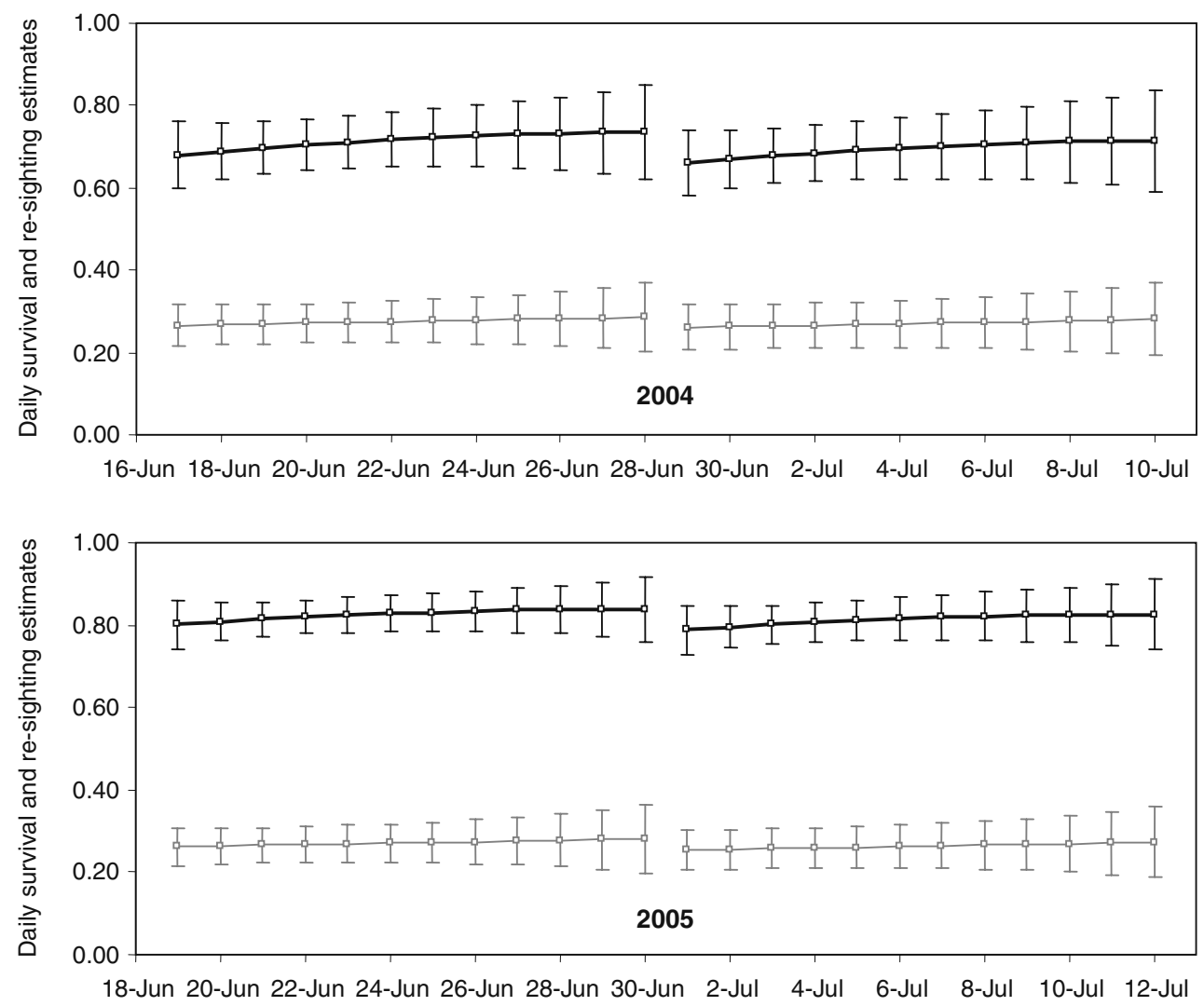

Fig. 1 Averaged real estimates (with SE) for introduced mallard ducklings in early and late treatments in 2004 (upper graph) and 2005 (lower graph). Black lines represent survival estimates and grey lines re-sighting estimates. Data from early and late treatment broods are separated by a break in the respective lines around June 29 in 2004 and July 1 in 2005. The only factor of clear importance to survival was year, with higher survival in 2005 than in 2004 (see "Results" for details) 

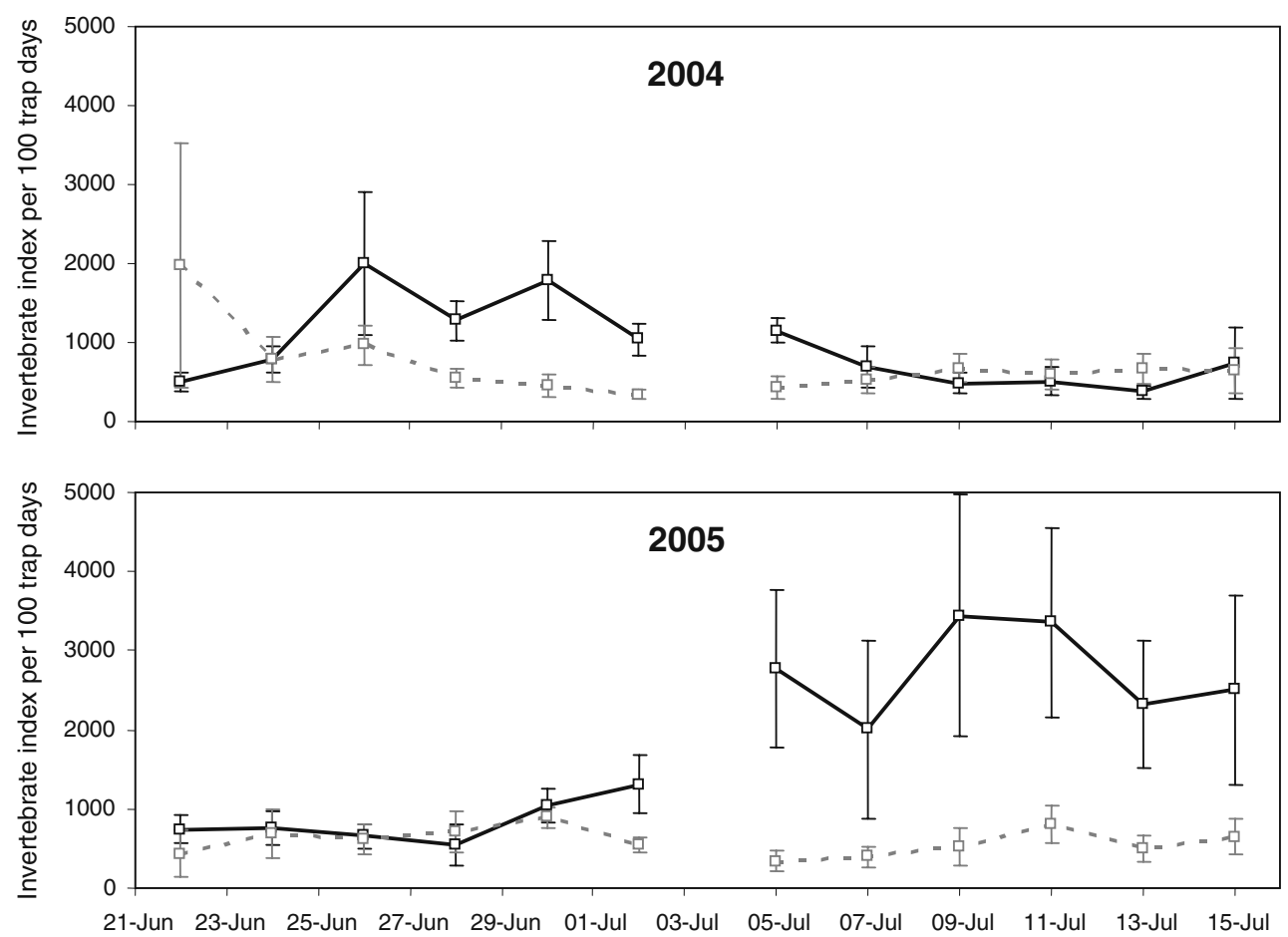

Fig. 2 Invertebrate index (with SE) per 100 trap days (see "Material and methods" for index details) for emergence traps (grey lines) and activity traps (black lines) in 2004 (upper graph) and 2005 (lower graph). Data from early and late treatment broods are separated by a break in the respective lines around June 29 in 2004 and July 1 in

find any support for hatching date effects on survival in common goldeneye (Bucephala clangula) ducklings. However, seasonal effects (i.e. timing of breeding) have been studied in other stages of the mallard's breeding cycle in Europe. For example, in an experimental study contrasting Mediterranean and boreal biomes, Elmberg et al. (2009) found that nest survival was higher in early treatments than in nests deployed later. For overall breeding success, though, it is final duckling production that is the most relevant aspect to study in a 'mismatch' context as driven by climate change, since, e.g. weather and food conditions are crucial for the survival of young ducklings in particular (Cox et al. 1998; Gunnarsson et al. 2004, 2006; Koskimies and Lahti 1964; Nummi et al. 2000; Sjöberg et al. 2000; see also further discussion below).

Mechanisms of season-dependent duckling survival, as described in many earlier studies, are not well understood, but seasonal declines have often been attributed to concomitant deterioration of wetland conditions and abundance (e.g. Dzus and Clark 1998; Hoekman et al. 2004; Krapu et al. 2000; Rotella and Ratti 1992a). Indeed, most of the observational studies come from the North American prairies, where seasonal wetlands (i.e. which dry up as the breeding season progresses) are common and where overall deterioration of habitat conditions during the breeding season is frequent. In line with this, Dzus and Clark
2005. Abundance of emergence trap invertebrates did not differ between treatments and years, in contrast to abundance of activity trap invertebrates, which differed between treatments in 2004 (see "Results")

(1998) reported an increase in mallard duckling survival in 1 year when abundance of seasonal wetlands increased exceptionally over the season. Gendron and Clark (2002) concluded that the absence of season-dependent duckling survival in their study may have been related to stable wetland conditions in the two study years. In addition, Simpson et al. (2005) did not find a seasonal decline in mallard duckling survival in the Great Lakes region, and these authors, too, attributed this pattern to relatively stable wetland conditions. Our experimental results suggest that season-dependent duckling survival found in many observational studies is likely due to deteriorating habitat conditions. We thus find support for the 'declining habitat condition' hypothesis, in the sense that the boreal lakes used by us do not undergo such seasonal changes in habitat condition (i.e. they do not dry up and do not even vary much in water level during the breeding season) and neither was duckling survival season dependent.

Did our study design introduce any confounding factor that prevented us from detecting a seasonal effect on duckling survival? As declared above (see "Eggs, ducklings and introductions"), body condition (i.e. body mass corrected for structural size) of females and body mass of ducklings differed between treatments (only in 2004 for ducklings), which, one could argue, might affect the outcome. This seems not to be the case, though, since 
these differences did not relate consistently to the absence of a treatment effect on duckling survival. However, the overall higher body mass of ducklings in 2005 as compared to 2004 may have led to the observed higher survival rates in the same year.

Our experiment took advantage of the natural variation in clutch initiation date among female mallards. We delayed hatching 12 days, which may not seem much compared to the natural variation (Batt and Prince 1979; Hill 1984; Oja and Pöysä 2007). However, in terms of predicted climate change, this is a truly significant difference in phenology. For example, Both and te Marvelde (2007) modelled trends in laying date in relation to recent climate change for the European starling (Sturnus vulgaris) and the pied flycatcher (Ficedula hypoleuca) across Europe. The predicted laying date changes ranged, depending on location, from 4 days delay to 7 days advance over a 25-year period (1984 to 2004). It should be noted that the length of the period during which seasonal effects on duckling survival was addressed varied much more in two observational studies that, like our experiment, did not find a seasonal decline in survival-59-80 days (within a season) in Gendron and Clark (2002) and 33-96 days in Simpson et al. (2005). These observational studies evidently included re-nesting attempts, but still did not find lower survival in late-hatched broods. Hence, we argue that the possibility of detecting season-dependent survival in our experiment most probably was not limited by the time difference between treatments. Nor did the storing of late-hatched eggs affect their quality, since we did not find any differences in hatching success between the treatments.

As demonstrated in previous experiments (Gunnarsson et al. 2004; see also Nummi et al. 2000; Sjöberg et al. 2000), food abundance may limit duckling survival on lakes of this type (i.e. same region, similar nutrient status and lake size). We therefore argue that our study design permits resource-related seasonal effects on duckling survival to be detected, if such indeed exist. Likewise, we hypothesise that the amount of available invertebrate prey, together with higher overall body mass of ducklings (see above), possibly had a positive effect on duckling survival, since both were higher in 2005 than in 2004. That food abundance is crucial to mallard duckling survival has previously been demonstrated by others in different study systems. For example, Cox et al. (1998) found that growth of young mallard ducklings was sensitive to variation in food invertebrate abundance and that duckling survival, in turn, was positively related to growth. In addition to food limitation, oligotrophic lakes in boreal environments have sparse emergent vegetation (Kauppinen and Väisänen 1993), and this may adversely affect mallard duckling survival by decreased thermoregulation during inclement weather or by providing less cover from predators
(Gunnarsson et al. 2006; Koskimies and Lahti 1964; Rhymer 1988; Simpson et al. 2007; Stafford and Pearse 2007). Although we do not know the ultimate fate of the ducklings in our study, predation likely had an additive effect on mortality (cf. Gunnarsson et al. 2004).

Mallard hens were wing-clipped for recognition, but also to discourage them from leaving the introduction lake with their brood. Most of the ducklings that were not observed after release hence most likely died on the lakes. In this respect, our manipulation does not resemble a natural situation, in which wild hens may take their broods to better foraging lakes (e.g. Ball et al. 1975; Dzus and Clark 1997; Rotella and Ratti 1992b). Yet, this should not cause any bias in the comparison between early-hatched and latehatched ducklings in our experiment. On the contrary, brood movements and overland travel in particular may be a severe confounding factor in observational studies done in prairie areas dominated by seasonal wetlands; movements may increase as seasonal wetlands dry up with time, thereby increasing predation risk (see discussion in Hoekman et al. 2004). Our experiment was designed to control for this problem and helped in studying the timing hypothesis per se.

Our findings have important bearings on the assessment of global climate change impact on population processes in ducks. Timing of breeding is closely associated with spring phenology in the mallard and other duck species, clutch initiation being earlier in early than in late springs (Drever and Clark 2007; Oja and Pöysä 2007 and references therein). However, the capacity of mallards to track changes in spring phenology may be imperfect; Oja and Pöysä (2007) found that the time interval between hatching date and ice break-up date decreased with increasing lateness of the spring. This suggests that there is a potential for a 'mismatch' between hatching phenology and resource phenology also in ducks, as has been found in for example some passerine and grouse species (Laaksonen et al. 2006; Ludwig et al. 2006; Visser et al. 1998). Peak emergence of chironomids, the main food of newly hatched ducklings, has traditionally been considered important to the timing of hatching in mallard and other ducks breeding in the boreal region (Danell and Sjöberg 1977; Hill 1984). However, just like Dessborn et al. (2009), the present study did not reveal any consistent peaks or other strong within-season trends in invertebrate abundance. In other words, mallards probably have a rather wide time window and a flexibility to tolerate a moderate mismatch between hatching phenology and resource phenology without fitness consequences, at least during the brood stage and in relatively stable boreal breeding environments. We are aware of only one study explicitly addressing the mismatch hypothesis in ducks. Using observational data of nest success, Drever and Clark (2007) found that relative (i.e. within season) clutch 
initiation date generally did not affect nest success in five duck species, including the mallard, breeding in prairies in Saskatchewan, Canada. These authors found evidence consistent with the mismatch hypothesis in only one species, the northern pintail (Anas acuta), and even here it was weak. Drever and Clark's (2007) and our results together suggest that breeding ducks by and large have considerable flexibility to tolerate variation in the timing of spring and resource phenology.

Model simulations have shown that increased drought will be a major climate-driven threat to waterfowl habitats and populations in the North American Prairies (Johnson et al. 2005; Sorenson et al. 1998). The conditions for these widespread species are, however, different in other parts of the northern hemisphere. For example, a drought scenario affecting waterfowl seems unlikely in large parts of Eurasia, where breeding waters are generally deeper and have more stable water levels than in North America, within as well as between years. However, as spring temperatures during the past two decades have risen faster in Eurasia than in North America (Piao et al. 2008), also other climate-driven constraints on reproductive performance of ducks may differ between the continents. Waterfowl are considered an important natural resource in North America, and recreational hunting of waterfowl is widespread worldwide (Kanstrup 2006; Kear et al. 2005). Sustainable management of waterfowl populations is thus a challenging task even without global climate change (e.g. Elmberg et al. 2006; Johnson et al. 1997; Nichols et al. 1995; Pöysä et al. 2004). Consequently, in order to better understand and predict climate change impact on duck populations, more research is needed, preferably manipulative experiments addressing the flexibility of breeding ducks to respond to climatedriven changes in resource phenology.

Acknowledgements We sincerely thank Göran Karlsson for skilful work with eggs and ducks at the Boda Game Station. Per Wedholm, Eric Andersson, Johan Nilsson and Åke Nordström are gratefully acknowledged for field work assistance. The research was supported by grant V 98-04 from The Swedish Environmental Protection Agency (Naturvårdsverket).

\section{References}

Arnold TW (2010) Uninformative parameters and model selection using Akaike's information criterion. J Wildl Manage 74:11751178

Arnold JM, HJ J, Nisbet CT (2004) Seasonal declines in reproductive success of the common tern Sterna hirundo: timing or parental quality? J Avian Biol 35:33-45

Ball IJ, Gilmer DS, Cowardin LM, Riechmann JH (1975) Survival of wood duck and mallard broods in north-central Minnesota. J Wildl Manage 39:776-780

Batt BDJ, Prince HH (1979) Laying dates, clutch size and egg weight of captive mallards. Condor 81:35-41
Both C, te Marvelde L (2007) Climate change and timing of avian breeding and migration throughout Europe. Clim Res 35:93-105

Both C, Artemyev AV, Blaauw B, Cowie RJ, Dekhuijzen AJ, Eeva T, Enemar A, Gustafsson L, Ivankina EV, Järvinen A, Metcalfe NB, Nyholm NEI, Potti J, Ravussin P-A, Sanz JJ, Silverin B, Slater FM, Sokolov LV, Török J, Winkel W, Wright J, Zang H, Visser ME (2004) Large-scale geographical variation confirms that climate change causes birds to lay earlier. Proc R Soc Biol Sci Ser B 271:1657-1662

Both C, Biljsma RG, Visser ME (2005) Climatic effects on timing of spring migration and breeding in a long-distance migrant, the pied flycatcher Ficedula hypoleuca. J Avian Biol 36:368-373

Brinkhof MWG, Cavé AJ, Hage FJ, Verhulst S (1993) Timing of reproduction and fledging success in the coot Fulica atra: evidence for a causal relationship. J Anim Ecol 62:577-587

Brown JL, Shou-Shien L, Bhagabati N (1999) Long-term trend toward earlier breeding in an American bird: a response to global warming? PNAS 96:5565-5569

Burnham KP, Anderson DR (2002) Model selection and multi-model inference: a practical information-theoretic approach, 2nd edn. Springer, New York

Chouinard MP Jr, Arnold TW (2007) Survival and habitat use of mallard (Anas platyrhynchos) broods in the San Joaquin Valley, California. Auk 1305-1316:1305-1316

Clutton-Brock TH (1988) Reproductive success. In: Clutton-Brock TH (ed) Reproductive success. University Chicago Press, Chicago, pp 472-486

Cox RR, Hanson MA, Roy CC, Euliss NH, Johnson DH, Butler MG (1998) Mallard duckling growth and survival in relation to aquatic invertebrates. J Wildl Manage 62:124-133

Cramp S, Simmons KEL (1977) The birds of the western Palearctic. Clarendon, Oxford

Crick HQP, Wingfield Gibbons D, Magrath RD (1993) Seasonal changes in clutch size in British birds. J Anim Ecol 62:263-273

Cunningham EJA, Russell AF (2000) Egg investment is influenced by male attractiveness in the mallard. Nature 404:74-77

Danell K, Sjöberg K (1977) Seasonal emergence of chironomids in relation to egglaying and hatching in a restored lake (northern Sweden). Wildfowl 28:129-135

Dessborn L, Elmberg J, Nummi P, Pöysä H, Sjöberg K (2009) Hatching in dabbling ducks and emergence in chironomids: a case of predator-prey synchrony? Hydrobiologia 636:319-329

Doherty PF Jr, Nichols JD, Tuatin J, Voelzer JF, Smith GW, Benning DS, Bentley VR, Bidwell JK, Bollinger KS, Brazda AR, Buelna EK, Goldsberry JR, King RJ, Roetker FH, Solberg JW, Thorpe PP, Wortham JS (2002) Sources of variation in breeding-ground fidelity of mallards (Anas platyrhynchos). Behav Ecol 13:543550

Drever MC, Clark RG (2007) Spring temperature, clutch initiation date and duck nest success: a test of the mismatch hypothesis. J Anim Ecol 76:139-148

Dunn PO, Winkler DW (1999) Climate change has affected the breeding date of tree swallows throughout North America. Proc R Soc Biol Sci Ser B 266:2487-2490

Dzus EH, Clark RG (1997) Overland travel, food abundance, and wetland use by mallards: relationships with offspring survival. Wilson Bull 109:504-515

Dzus EH, Clark RG (1998) Brood survival and recruitment of mallards in relation to wetland density and hatching date. Auk 115:311-318

Elmberg J, Nummi P, Pöysä H, Sjöberg K (1992) Do intruding predators and trap position affect the reliability of catches in activity traps? Hydrobiologia 239:187-193

Elmberg J, Nummi P, Pöysä H, Sjöberg K (1993) Factors affecting species number and density of dabbling duck guilds in North Europe. Ecography 16:251-260 
Elmberg J, Gunnarsson G, Pöysä H, Sjöberg K, Nummi P (2005a) Within-season sequential density dependence regulates breeding success in mallards Anas platyrhynchos. Oikos 108:582590

Elmberg J, Nummi P, Pöysä H, Gunnarsson G, Sjöberg K (2005b) Early breeding teal Anas crecca use the best lakes and have the highest reproductive success. Annales Zoologici Fennici 42:3743

Elmberg J, Nummi P, Pöysä H, Sjöberg K, Gunnarsson G, Clausen P, Guillemain M, Rodrigues D, Väänänen V-M (2006) The scientific basis for a new and sustainable management of migratory European ducks. Wildl Biol 12:121-127

Elmberg J, Folkesson K, Guillemain M, Gunnarsson G (2009) Putting density dependence in perspective: nest density, nesting phenology, and biome, all matter to survival of simulated mallard Anas platyrhynchos nests. J Avian Biol 40:317-326

Fransson T, Pettersson J (2001) Svensk ringmärkningsatlas [Swedish bird ringing atlas]. Ljungföretagen Tryckeri AB, Örebro

Gendron M, Clark RG (2002) Survival of gadwall and mallard ducklings in southcentral Saskatchewan. J Wildl Manag 66:170 180

Gunnarsson G, Elmberg J, Sjöberg K, Pöysä H, Nummi P (2004) Why are there so many empty lakes? Food limits survival of mallard ducklings. Can J Zool 82:1698-1703

Gunnarsson G, Elmberg J, Sjöberg K, Pöysä H, Nummi P (2006) Experimental evidence for density-dependent survival in mallard (Anas platyrhynchos) ducklings. Oecologia 149:203-213

Hamann J, Cooke F (1989) Intra-seasonal decline of clutch size in lesser snow geese. Oecologia 79:83-90

Hansson B, Bensch S, Hasselquist D (2000) The quality and timing hypotheses evaluated using data on great reed warblers. Oikos 90:575-581

Heaney V, Monaghan P (1995) A within-clutch trade-off between egg production and rearing in birds. Proc R Soc Biol Sci Ser B 261:361-365

Hill DA (1984) Laying date, clutch size and egg size of the mallard Anas platyrhynchos and tufted duck Aythya fuligula. Ibis 126:484-495

Hill D, Wright R, Street M (1987) Survival of mallard ducklings Anas platyrhynchos and competition with fish for invertebrates on a flooded gravel quarry in England. Ibis 129:159-167

Hoekman ST, Gabor TS, Maher R, Murkin HR, Armstrong LM (2004) Factors affecting survival of mallard ducklings in southern Ontario. Condor 106:485-495

Johnson FA, Moore CT, Kendall WL, Dubovsky JA, Caithamer DF, Kelley JR, Williams BK (1997) Uncertainty and the management of mallard harvests. J Wildl Manag 61:202-216

Johnson WC, Millett BV, Gilmanov T, Voldseth RA, Guntenspergen GR, Naugle DE (2005) Vulnerability of northern prairie wetlands to climate change. Bioscience 55:863-872

Kanstrup N (2006) Sustainable harvest of waterbirds: a global review. In: Boere GC, Calbraith CA, Stroud DA (eds) Waterbirds around the world. The Stationery Office, Edinburgh, pp 98-106

Kauppinen J (1993) Densities and habitat distribution of breeding waterfowl in boreal lakes in Finland. Finn Game Res 48:24-45

Kauppinen J, Väisänen RA (1993) Ordination and classification of waterfowl communities in south boreal lakes. Finn Game Res 48:3-23

Kear J, Jones T, Matthews GVT (2005) Conservation and management. In: Kear J (ed) Ducks, geese and swans, vol 1. Oxford University Press, New York, pp 152-171

Klomp H (1970) The determination of clutch-size in birds. Ardea $58: 1-124$

Koskimies J, Lahti L (1964) Cold-hardiness of the newly hatched young in relation to ecology and distribution in ten species of European ducks. Auk 81:281-307
Koskimies P, Väisänen R (1991) Monitoring bird populations. Zoological Museum, Finnish Museum of Natural History, Helsinki

Krapu GL, Pietz PJ, Brandt DA, Cox RR (2000) Factors limiting mallard brood survival in prairie pothole landscapes. J Wildl Manag 64:553-561

Laaksonen T, Ahola M, Eeva T, Väisänen RA, Lehikoinen E (2006) Climate change, migratory connectivity and changes in laying date and clutch size of the pied flycatcher. Oikos 114:277-290

Laurila T, Hario M (1988) Environmental and genetic factors influencing clutch size, egg volume, date of laying and female weight in the common eider Somateria mollissima. Finn Game Res 45:19-30

Lebreton J-D, Burnham KP, Clobert J, Anderson DR (1992) Modelling survival and testing biological hypotheses using marked animals: a unified approach with case studies. Ecol Monogr 62:67-118

Lepage D, Desroches A, Gauthier G (1999) Seasonal decline of growth and fledging success in snow geese Anser caerulescens: an effect of date or parental quality? J Avian Biol 30:72-78

Lessells CM (1991) The evolution of life histories. In: Krebs JR, Davies NB (eds) Behavioural ecology: an evolutionary approach. Blackwell, Oxford, pp 32-68

Lindén M, Møller AP (1989) Cost of reproduction and covariation of lifehistory traits in birds. Trends Ecol Evol 4:367-371

Ludwig GX, Alatalo RV, Helle P, Lindén H, Lindström J, Siitari H (2006) Short- and long-term population dynamical consequences of asymmetric climate change in black grouse. Proc R Soc Biol Sci Ser B 273:2009-2016

Mauser DM, Jarvis RL, Gilmer DS (1994) Survival of radio-marked mallard ducklings in northeastern California. J Wildl Manag 58:82-87

Milonoff M, Pöysä H, Virtanen J (1995) Brood-size-dependent offspring mortality in common goldeneyes reconsidered: fact or artifact? Am Nat 146:967-974

Møller AP (2008) Climate change and micro-geographic variation in laying date. Oecologia 155:845-857

Monaghan P, Nager RG (1997) Why don't birds lay more eggs? Trends Ecol Evol 12:270-274

Nichols JD, Johnson FA, Williams BK (1995) Managing North American waterfowl in the face of uncertainty. Annu Rev Ecol Syst 26:177-199

Nilsson J-Å (1999) Fitness consequences of timing of reproduction. In: Adams NJ, Slotow RH (eds) Proceedings of 22 international ornithological congress. BirdLife South Africa, Johannesburg, pp 234-247

Norris K (1993) Seasonal variation in the reproductive success of blue tits: an experimental study. J Anim Ecol 62:287-294

Nudds TD, Bowlby JN (1984) Predator-prey size relationships in North American dabbling ducks. Can J Zool 62:2002-2008

Nummi P, Sjöberg K, Pöysä H, Elmberg J (2000) Individual foraging behaviour indicates resource limitation: an experiment with mallard ducklings. Can J Zool 78:1891-1895

Oja H, Pöysä H (2007) Spring phenology, latitude, and the timing of breeding in two migratory ducks: implications of climate change impacts. Ann Zool Fenn 44:475-485

Orthmeyer DL, Ball IJ (1990) Survival of mallard broods on Benton Lake National Wildlife Refuge in northcentral Montana. J Wildl Manag 54:62-66

Paasivaara A, Pöysä H (2007) Survival of common goldeneye Bucephala clangula ducklings in relation to weather, timing of breeding, brood size, and female condition. J Avian Biol 38:144 152

Pearce-Higgins JW, Yalden DW, Whittingham MJ (2005) Warmer springs advance the breeding phenology of golden plovers 
Pluvialis apricaria and their prey (Tipulidae). Oecologia 143:470-476

Pearse AT, Ratti JT (2004) Effects of predator removal on mallard duckling survival. J Wildl Manag 68:342-350

Perrins CM (1970) The timing of birds' breeding season. Ibis 112:242-255

Piao S, Ciais P, Friedlingstein P, Peylin P, Reichstein M, Luyssaert S, Margolis H, Fang J, Barr A, Chen A, Grelle A, Hollinger DY, Laurila T, Lindroth A, Richardson AD, Vesala T (2008) Net carbon dioxide losses of northern ecosystems in response to autumn warming. Nature 451:49-52

Pöysä H, Elmberg J, Sjöberg K, Nummi P (1998) Habitat selection rules in breeding mallards (Anas platyrhynchos): a test of two competing hypotheses. Oecologia 114:283-287

Pöysä H, Elmberg J, Gunnarsson G, Nummi P, Sjöberg K (2004) Ecological basis of sustainable harvesting: is the prevailing paradigm of compensatory mortality still valid? Oikos 104:612615

Price T, Kirkpatrick M, Arnold SJ (1988) Directional selection and the evolution of breeding date in birds. Science 240:798-799

Rhymer JM (1988) The effect of egg size variability on thermoregulation of mallard (Anas platyrhynchos) offspring and its implications for survival. Oecologia 75:20-24

Ringelman JK, Flake LD (1980) Diurnal visibility and activity of blue-winged teal and mallard broods. J Wildl Manag 44:822-829

Rohwer F (1992) The evolution of reproductive patterns in waterfowl. In: Batt BDJ, Afton AD, Anderson MG, Ankney CD, Johnson DH, Kadlec JA, Krapu GL (eds) Ecology and management of breeding waterfowl. University Minnesota Press, Minneapolis, pp 486-539

Rotella JJ, Ratti JT (1992a) Mallard brood survival and wetland habitat conditions in southwestern Manitoba. J Wildl Manag 56:499-507

Rotella JJ, Ratti JT (1992b) Mallard brood movements and wetland selection in southwestern Manitoba. J Wildl Manag 56:508-515

Sayler RD, Willms MA (1997) Brood ecology of mallards and gadwalls nesting on islands in large reservoirs. J Wildl Manag 61:808-815

Schoech SJ, Hahn TP (2008) Latitude affects degree of advancement in laying by birds in response to food supplementation: a metaanalysis. Oecologia 157:369-376

Sedinger JS (1992) Ecology of prefledgling waterfowl. In: Batt BDJ, Afton AD, Anderson MG, Ankney CD, Johnson DH, Kadlec JA,
Krapu GL (eds) Ecology and management of breeding waterfowl. University of Minnesota Press, Minneapolis, pp 109-127

Simpson JW, Yerkes TJ, Smith BD, Nudds TD (2005) Mallard duckling survival in the Great Lakes region. Condor 107:898909

Simpson JW, Yerkes TJ, Nudds TD, Smith BD (2007) Effects of habitat on mallard duckling survival in the Great Lakes region. J Wildl Manag 71:1885-1891

Sjöberg K, Pöysä H, Elmberg J, Nummi P (2000) Response of mallard ducklings to variation in habitat quality - an experiment of food limitation. Ecology 81:329-335

Sorenson LG, Goldberg R, Root TL, Anderson MG (1998) Potential effects of global warming on waterfowl populations breeding in the Northern Great Plains. Climate Change 40:343-369

Stafford JD, Pearse AT (2007) Survival of radio-marked mallard ducklings in South Dakota. Wilson J Ornithology 119:585-591

Stafford JD, Flake LD, Mammenga PW (2002) Survival of mallard broods and ducklings departing overwater nesting structures in eastern South Dakota. Wildl Soc Bull 30:327-336

Torti VM, Dunn PO (2005) Variable effects of climate change on six species of North American birds. Oecologia 145:486-495

Verhulst S, Nilsson J- $\AA$ (2008) The timing of birds' breeding season: a review of experiments that manipulated timing of breeding. Philos Trans R Soc Lond B Biol Sci 363:399-410

Verhulst S, Tinbergen JM (1991) Experimental evidence for a causal relationship between timing and success of reproduction in the great tit Parus m. major. J Anim Ecol 60:269-282

Verhulst S, van Balen JH, Tinbergen JM (1995) Seasonal decline in reproductive success of the great tit: variation in time or quality? Ecology 76:2392-2403

Visser ME, van Noordwijk AJ, Tinbergen JM, Lessells CM (1998) Warmer springs lead to mistimed reproduction in great tits (Parus major). Proc R Soc Biol Sci Ser B 265:1867-1870

Visser ME, Adriaensen F, van Balen JH, Blondel J, Dhondt AA, van Dongen S, du Feu C, Ivankina EV, Kerimov AB, de Laet J, Matthysen E, McCleery R, Orell M, Thomson DL (2003) Variable responses to large-scale climate change in European Parus populations. Proc R Soc Biol Sci Ser B 270:367-372

Weatherhead PJ (2005) Effects of climate variation on timing of nesting, reproductive success, and offspring sex ratios of redwinged blackbirds. Oecologia 144:168-175

White GC, Burnham KP (1999) Program MARK: survival estimation from populations of marked animals. Bird Study Suppl 46:120-139 